\title{
21 de maio: Dia Mundial da Diversidade Cultural \\ Diversidade Cultural e Sustentabilidade Socioambiental, na perspectiva da encíclica 'Laudato Si'
}

\section{Camila Lassance}

Pedro Edson Constantino Corrale (Estudantes de Relações Internacionais no IRI PUC Rio)

Em 20 de Dezembro de 2003, a resolução 57/249 que versa sobre "Cultura e Desenvolvimento", foi base para que a ONU - Organização das Nações Unidas, através da Unesco, órgão da ONU para o desenvolvimento da educação, da ciência e da cultura, decidisse proclamar, em sua Assembleia Geral, o dia 21 de Maio como o Dia Mundial da Diversidade Cultural para o Diálogo e o Desenvolvimento. O então diretor-geral da Unesco, Koïchiro Matsuura, leu uma carta de proclamação e convidou todos os Estados-membros, as organizações intergovernamentais, as organizações das Nações Unidas e as organizações não governamentais competentes, a, entre outras, sensibilizar a opinião pública para a riqueza da diversidade cultural e, particularmente, a suscitar, através da educação e dos meios de comunicação, uma tomada de consciência do valor da diversidade cultural. Assim, o 21 de maio passou a ser celebrado por todos os Estados-membros há 15 anos. O então diretor-geral, ressaltou que a celebração sublinhou o Ato Constitutivo da Unesco, que prevê, desde a sua criação, a missão de promover a fecunda diversidade e respeito entre os povos.

Em seu discurso de 21 de maio de 2004, em Lisboa, no primeiro ano de celebração, Matsuura lembrou que as culturas de um modo geral estavam ameaçadas no mundo todo, por diversos fatores, entre os quais, a defesa abusiva de uma busca de identidade nacional que se opunha à existência de grupos minoritários, os excessos cometidos em nome da religião, os efeitos da globalização, entre outros. Para o diretor-geral, a perda de um processo civilizador baseado na diversidade compromete o patrimônio imaterial das futuras gerações e põe em risco, inclusive, a sobrevivência da própria espécie humana. 
A resolução, que teve como base a celebração do 21 de maio, foi publicada em 2001, e consolidada como a Declaração Universal da Unesco sobre a Diversidade Cultural, que define 20 linhas essenciais de um Plano de Ação, que prevê uma nova compreensão da relação entre diversidade, diálogo e desenvolvimento. Diversidade, diálogo e desenvolvimento, são elementos solidários de um sistema para otimizar os recursos culturais da humanidade, segundo o diretor-geral. As representações regionais da Unesco nos Estados-membros, se encarregaram de secundar ou animar tais iniciativas, estabelecendo novas parcerias com a sociedade civil.

"A Declaração Universal da Unesco sobre a Diversidade Cultural é um importante instrumento para o diálogo e o desenvolvimento. Cada um deve levar a mensagem para a sua sociedade, para que o pluralismo cultural possa tornar-se, através do diálogo de culturas, uma riqueza partilhada. Só assim evitaremos rupturas trágicas e poderemos esperar atingir um desenvolvimento sustentável, garantido pela sustentabilidade da diversidade cultural e pela prossecução de um diálogo construtivo e vigilante", discursou Matsuura na época.

\section{O Caminho pelo Diálogo}

A riqueza cultural do mundo reside em sua diversidade, diversidade que só se faz possível através do diálogo. A diversidade flui ao longo do tempo, ao longo da história da própria humanidade. Reconhecer a diferença do outro, significa compartilhar, significa não fazer guerra, significa a não agressão mútua, o que só possível através do diálogo.

A Declaração Universal da Unesco sobre a Diversidade Cultural, foi aprovada por unanimidade em uma conjuntura muito singular: logo após os acontecimentos de 11 de setembro de 2001, ou seja, dos ataques às Torres Gêmeas nos Estados Unidos. A Declaração surgiu na $31^{\text {a }}$ reunião da Conferência Geral da Unesco, o primeiro grande encontro de nível internacional depois daqueles ataques motivados pelo terror. A proposta era ver, diante do caos, a oportunidade de reafirmar a convicção de que o diálogo intercultural é a melhor garantia da paz, e de rechaçar categoricamente a teoria de um inevitável choque de culturas e civilizações. 
Com a Declaração, um instrumento novo para a comunidade internacional, elevou a diversidade cultural à categoria de patrimônio comum da humanidade, tão necessário para a humanidade como a biodiversidade biológica para os organismos vivos, e cuja defesa é um imperativo ético indissociável do respeito à dignidade humana de modo geral e individual.

A Declaração pretendeu preservar esse tesouro vivo e, portanto, renovável, que é a diversidade cultural, diversidade que não cabe entender como patrimônio estático e sim como processo que garante a sobrevivência da humanidade. Busca também evitar toda segregação e fundamentalismo que, em nome das diferenças culturais, as sacralize, desvirtuando assim a mensagem da Declaração Universal dos Direitos Humanos, intrinsicamente relacionada.

A Declaração destaca o fato de que cada indivíduo deve reconhecer não apenas a alteridade em todas as suas formas, mas também o caráter plural de sua própria identidade dentro de sociedades igualmente plurais. Somente dessa forma é possível conservar a diversidade cultural em sua dupla dimensão de processo evolutivo e fonte de expressão, criação e inovação. Assim, fica superado o debate entre os países que desejam defender os bens e serviços culturais que, por serem portadores de identidade, valores e sentido, não devem ser considerados mercadorias ou bens de consumo como os demais, e aqueles que esperavam fomentar os direitos culturais, pois a Declaração conjuga essas duas aspirações complementares, destacando o nexo causal que as une: uma não pode existir sem a outra. A Declaração se opõe ao fechamento fundamentalista e vê a perspectiva de um mundo mais aberto, criativo e democrático, sendo um texto fundador de uma nova ética.

\section{A Diversidade na Perspectiva da Laudato Si}

Em seu primeiro capítulo, 'O que está a acontecer em nossa Casa', a Encíclica Laudato Si, escrita pelo Papa Francisco, aponta de um modo geral os principais problemas que afligem a humanidade. Nele, o Papa ressalta o risco da destruição da biodiversidade, os problemas específicos que se relacionam ao clima e à água, aponta a degradação social, a desigualdade 
econômica e social, e analisa como o esgotamento dos recursos conflagra conflitos, guerras, provocando ainda mais destruição e retrocessos para a humanidade. O Papa Francisco aponta a não solidariedade como grande responsável por tantos problemas crescentes, lembrando dos excessos do sistema capitalista e sua exploração econômica desenfreada. Francisco aponta que discursos extremistas que não solucionam os problemas reais, apenas promovem mitos e aceleram ainda mais os conflitos, e exaltam ainda mais os ânimos. Francisco lembra que o excesso de opinião não solidária, não apenas não contribui para a evolução da sociedade, como cria novas gerações mais desesperançosas e sem perspectivas. Para o Papa, se faz necessário um diálogo honesto entre as Nações.

Se a Encíclica prevê o diálogo honesto, o não conflito como meio de resolução dos sérios problemas humanos, o respeito à diversidade é, sem dúvidas, o caminho para uma nova sociedade ética, de modo que a resolução da ONU através da Unesco, vai de encontro com a Encíclica de Francisco, assim como a celebração do 21 de Maio em todo o mundo.

Crimes de ódio e seus discursos também de ódio, humilhações, discriminações e preconceitos, racismo por etnia ou religioso, não aceitação da diversidade de gênero e sexual, agressão às mulheres, ataques aos índios, a estrangeiros, aos ativistas sociais, ataques às pessoas, aos seus guetos e suas nações, tudo seria estancado com o verdadeiro diálogo e a verdadeira celebração da diversidade.

Assim, recordando o Preâmbulo da Constituição da Unesco, que afirma “(...) que a ampla difusão da cultura e da educação da humanidade para a justiça, a liberdade e a paz são indispensáveis para a dignidade do homem e constituem um dever sagrado que todas as nações devem cumprir com um espírito de responsabilidade e de ajuda mútua".

Reconhecer a unidade na diferença, é o único caminho para a evolução, e para fazer valer tanto a Declaração Universal dos Direitos Humanos, assim como a Encíclica Laudato Si.

\section{A Raiz Está na Cultura}

A Declaração Universal da Diversidade Cultural, nos principais e primeiros artigos, define muito bem o que é cultura e como a cultura se 
dissemina entre as gerações em centenas de anos, e qual a importância da sua preservação e respeito pelo diálogo, assim como as condições para sua expressão, ato imprescindível para sua consolidação na vida cotidiana do ser humano, em qualquer parte do mundo.

A Declaração reafirma que a cultura deve ser considerada como o conjunto dos traços distintivos espirituais e materiais, intelectuais e afetivos que caracterizam uma sociedade ou um grupo social e que abrange, além das artes e das letras, os modos de vida, as maneiras de viver juntos, os sistemas de valores, as tradições e as crenças.

Também constata que a cultura se encontra no centro dos debates contemporâneos sobre a identidade, a coesão social e o desenvolvimento de uma economia fundada no saber, adquirindo formas diversas através do tempo e do espaço.

Lembra que a diversidade se manifesta na originalidade e na pluralidade de identidades que caracterizam os grupos e as sociedades que compõem a humanidade. Afirma que, fonte de intercâmbios, de inovação e de criatividade, a diversidade cultural é, para o gênero humano, tão necessária como a diversidade biológica para a natureza. Nesse sentido, constitui o patrimônio comum da humanidade, e prisma para que deva ser reconhecida e consolidada em benefício das gerações presentes e futuras.

A aposta ética eficaz se realiza no âmbito da diversidade e do pluralismo cultural, com sociedades cada vez mais diversificadas, sendo indispensável garantir uma interação harmoniosa entre pessoas e grupos com identidades culturais a um só tempo plurais, variadas e dinâmicas, assim como sua vontade de conviver ao mesmo tempo com características tão peculiares e distintas.

A Declaração propõe que todo o fazer político favoreça a inclusão e a participação de todos os cidadãos, ou seja, sua coesão social, tão essencial para a vitalidade da sociedade civil e a paz. Definido desta maneira, o pluralismo cultural constitui a resposta política à realidade da diversidade cultural, e é inseparável de um contexto democrático. A democracia, o pluralismo cultural, é propício aos intercâmbios culturais e ao desenvolvimento das capacidades criadoras que alimentam a vida pública. 
A diversidade cultural amplia as possibilidades de escolha que se oferecem a todos, tornando-se uma das fontes do desenvolvimento, entendido não somente em termos de crescimento econômico, mas também como meio de acesso a uma existência intelectual, afetiva, moral e espiritual satisfatória, assim como propõe a Encíclica Laudato Si.

A defesa da diversidade cultural é um imperativo ético, inseparável do respeito à dignidade humana. Ela implica o compromisso de respeitar os direitos humanos e as liberdades fundamentais, em particular os direitos das pessoas que pertencem a minorias e os aos povos autóctones. Ninguém pode invocar a diversidade cultural para violar os direitos humanos garantidos pelo direito internacional, nem para limitar seu alcance.

Os direitos culturais são parte integrante dos direitos humanos, que são universais, indissociáveis e interdependentes. O desenvolvimento de uma diversidade criativa exige a plena realização dos direitos culturais, tal como prevê a Declaração Universal dos Direitos Humanos.

Toda pessoa deve, assim, poder expressar-se, criar e difundir suas obras na língua que deseje e, em particular, na sua língua materna. Toda pessoa tem direito a uma educação e uma formação de qualidade que respeite plenamente sua identidade cultural. Toda pessoa deve poder participar na vida cultural que escolha e exercer suas próprias práticas culturais, dentro dos limites que impõe o respeito aos direitos humanos e às liberdades fundamentais.

Enquanto se garanta a livre circulação das ideias mediante a palavra e a imagem, deve-se cuidar para que todas as culturas possam se expressar e se fazer conhecidas. A liberdade de expressão, o pluralismo dos meios de comunicação, o multilingüismo, a igualdade de acesso às expressões artísticas, ao conhecimento científico e tecnológico - inclusive em formato digital - e a possibilidade, para todas as culturas, de estar presentes nos meios de expressão e de difusão, são garantias da diversidade cultural.

\section{O espírito de solidariedade}

Não existirá respeito nem diversidade ou debate de ideias, sem o espírito universal de solidariedade. O Dia Mundial da Diversidade Cultural 
propõe que todas as Nações trabalhem esse valor, como base para fundação de uma sociedade mundial que respeite a diversidade cultural.

A proposta da celebração é criar núcleos que se disseminem levando luz à ideia solidária, transformando a essência do ser, revertendo valores, revertendo atitudes hostis.

O Dia 21 de Maio, ainda pouco difundido e celebrado, requer mais atenção, pois é um recurso para dialogar com diferentes nações de modo isento, visto que a data não está vinculada a uma religião ou congregação política ou ideológica, mas fundada democraticamente por Estados-membros diversos, e fundamentada na Declaração Universal dos Direitos Humanos, e no campo das boas relações internacionais.

\section{Bibliografia}

Assembleia Geral da Organização das Nações Unidas - ONU, de 20/12/2003, New York.

Conferência Geral da Unesco, 31ª reunião, 11/2001, Paris.

Constituição da Organização das Nações Unidas para a Educação, a Ciência e a Cultura, 1945-2002,New York-Paris.

Declaração Universal sobre a Diversidade Cultural (resolução 57/249), Unesco, 2002, Paris.

Matsuura, Koïchiro. Pronunciamento na Unesco em 21/05/2004, Lisboa.

Papa Francisco. Encíclica Laudato Si, 24/05/2015, Vaticano. 